\title{
Making Space for Intuition in Decision Making: \\ The case of project prioritization
}

\begin{abstract}
Researchers and practitioners advocate strongly for the use of quantitative data and calculations of costs and benefits as the basis for organizational decision making. We investigate decision making in the form of project prioritization. We use a rich empirical dataset built from a longitudinal study of the prioritization of information technology projects in a large financial institution. Our findings indicate that during project prioritization meetings, senior decision makers apply a set of techniques to make space for the use of intuition in the decision process. We also describe how intuition is manifested during the meetings. Our empirical study provides evidence on the central role of intuition when solving loosely structured problems such as the ones encounter during information technology projects prioritization.
\end{abstract}

Key words: intuition, decision making, judgments, longitudinal study 


\section{INTRODUCTION}

A growing number of studies of decision making in organizations call for the use of more quantitative data to support rational decision making (e.g., Kahneman, 2011; Bazerman \& Moore, 2008). They highlight the importance of quantitative data, which estimate the economic impact of available options, and thereby, reduce the underlining problem of cognitive bias in decision making. Quantitative data can be processed by various financial and accounting models, and thereby, inform the decision making process by enabling comparative analysis of different options, forecast of future outcomes, or simulation of alternative scenarios.

Scholars in the area of information processing have repeatedly called for information systems to provide accurate information and to facilitate decision making (Brynjolfson et al., 2011; Davenport, 2010). A common feature of these studies is the understanding that the managers are empowered by quantitative data, an empowerment which in turn leads to analytical decisions, and therefore, better decisions (Pfeffer \& Sutton, 2006). Simultaneously, in a different stream of research several scholars advocate that the extensive use of quantitative data and rational decision models by decision-makers may lead organizations to adopt conservative strategies and support exploitation of existing competencies over exploration of new opportunities (March, 1991; Albin \& Foley, 1998). Other scholars advocate strongly for the importance of intuition in decision making for complex problem solving (Hammond et al., 1997; Hogarth, 2001). Their findings show that expert decision makers can use intuition effectively in complex problem solving related to their domain of expertise. These scholars underline the importance of intuition or "gut feeling" in the decision-making process by explaining how it provides holistic and accurate input, if the decision maker's context, from which experiences are collected, provided representative and valid feedback (Hogarth, 2001). Besides, recent advances in social cognitive neuroscience have shed a new light in research investigating the role of senior managers' intuition in strategy making and strategic management (Hodgkinson et al., 2008; Hodgkinson et al., 2009).

Building on the insights described above, the initial aim of the present study was to investigate how managers decide on project prioritizations. The issue of intuition in decision making came to our attention when, during interviews, decision makers repeatedly used expressions such as "my gut feeling says...", and thus, it seemed that they applied intuition when prioritizing projects. Most of them indicated a strong faith in their "gut feeling” albeit the formal criteria defined by the organization. As an interviewee explained: "At the end of the day I think that it is the stomach feeling ... well, if we ... believe in it." (Interview with 
Senior Business Representative 1, May 2010, page 11). Another interviewee described the role of hard facts and intuition in the prioritization process: "It [project prioritization] was more intuition than hard facts. It is more decision based on soft information, discussing what our appetite for this area is, and not really looking at the total benefits that this area provides...When managers argue about whether a project should be prioritized or not, the use of soft information and intuition, if customers would like this product or what is the appetite for products from a specific area, do we want to be strong in the area or do we just want to follow our competitors." (Interview with Senior Business Representative 2, November 2010, page 10). Using these observations as our point of departure, we investigate:

- How decision makers apply intuition during project prioritization meetings in an organization where quantitative data of cost-benefit analysis and rational decisionmaking are the canonized technologies?

Our aim is to contribute to the debate about intuitive versus analytical decision making (Kahneman, 2011; Kahneman \& Klein, 2009; Simon 1987). Our case involves an organization, where state-of-the-art IT solutions such as business intelligence systems are deployed to improve decision making, and where the decision makers have a wide repertoire of experiences and in-depth knowledge of the domain. We investigate how decisions are reached in the prioritization process, implying that we view project prioritization as an example of decision making. The empirical setting is a Scandinavian financial institution, and we use a rich dataset built from a longitudinal study, which covers a full circle of the IT project prioritization process in this organization. The IT projects in the case are characterized by high complexity, and uncertainty about their returns (Ballantine et al., 1999). IT projects' benefits are difficult to measure in an accurate and reliable manner. Thus, the underlining ambiguity of the information produced for the project prioritization challenges decision makers, since it seldom increases clarity.

The paper is structured as follows. First, we present the theoretical background and position our research. Second, we describe the setting for the empirical study. Third, we present the research method. This is followed by the analysis of the project prioritization process, and a discussion on the findings. Finally, we conclude and highlight the contribution, and future research directions.

\section{RESEARCH ON INTUITION AND DECISION-MAKING}

The role of intuition in decision making is profound. Nobel laureates in economics highlight the role of intuition in decision making, in the light of bounded rationality (Simon, 1955) or in 
relation to cognitive processes simplifying complex and information-intense tasks (Kahneman, 2003). Especially, Kahneman clearly described the role of the intuitive system of thinking in decision making, in his Nobel laureate lecture (2003).

\section{Two Perspectives on the Relationship Between Intuition and Decision Making}

In the literature we have identified two perspectives on the role of intuition in decision making. First, a number of cognitive psychologists (see Gilovich et al, 2002) and organization theorists (Bazerman \& Moore, 2008) frame intuition in relation to simplification of complex problem solving, involving heuristics which serve as shortcuts to reduce the decision maker's cognitive burden. This framing underlines the danger of cognitive biases, which may occur because of the simplification or the neglect of information about the environment and other cues, when individuals attempt to reach a decision by compromising accuracy to reduce the cognitive burden of a decision task (Payne et al,. 1993). The main argument in this perspective is that intuition is highly dependent on the decision maker's experiences, thus, past experience may lead to cognitive biases when the decision maker does not take into account the information available in the environment. Besides, negative experiences from prior failures may raise the probability of a wrong decision when using intuition. Thus, scholars propose ways to reduce the use of intuitive thinking (including heuristic biases) and increase decision makers' abilities to process more information from the environment and develop practices for rational decision making (Kahneman, 2011). Yet, cognitive psychologists also underline the efficiency of heuristics in relation to fast and frugal decisions (Gigerenzer et al., 1999).

The second perspective, which involves the naturalistic decision making (Klein et al., 1993; Crandall et al., 2006), perceives intuition as an alternative to deliberate modes of thinking (Hogarth, 2001) and clearly underlines the value of intuition in complex problem solving. These scholars emphasize the holistic nature of intuition, which they separate from the use of heuristics. Their main argument is that intuition, which is expressed as a feeling, serving as a basis for judgment, comes from the decision-makers experiences, stored in memory and built on the use of associative learning (Betsch, 2008). Common to these scholars' conceptions is that intuition provides better input into the judgment of less structured problems and increases accuracy of decisions. They suggest ways to educate and improve intuition by enhancing the learning contexts where the decision maker is exposed, thereby increasing his or her expertise (Hogarth, 2001). 
The two perspectives seem opposing. For example, when a decision maker makes a fast decision in a specific situation, this can be seen from the heuristics perspective as an indication of overconfidence (Moore \& Healy, 2008) or from an intuition perspective as an informed decision of an expert who has experienced repeatedly this situation in the past (Hogarth, 2001). However, Kahneman \& Klein (2009), two core representatives of the two different perspectives on intuition, recently revealed their consensus on the value of intuition of experts, under specific conditions, in the decision process. They used Simon's (1992) description of skilled intuition based on recognition, as a common ground, which they both endorse.

The debate between the two groups of scholars supporting and opposing the use of intuition by managers is evident both in practitioners' outlets providing short position papers of researchers' perspectives, and in scholarly journals. Milkmann et al. (2010) suggest some methods to leverage the intuitive thinking by providing the decision maker with cues enabling a shift to the analytical approach. Bonabeau (2003) acknowledges that the use of intuition by many managers is a decision tool that reduces the time spent on information processing and evaluating alternative options. However, he strongly advocates against it and proposes the use of software in the form of analytical tools. Intuition is praised as effective when managers have to make decisions, in real-time, dynamic environments such as information technology (Prewitt, 1998). Hayashi (2001) provide some practices for managers to sharpen their intuition and avoid the biases, and Mintzberg \& Westley (2001) identify three approaches to make decisions that are more or less adequate for different tasks. One of them involves an action-oriented intuitive approach, which is recommended for novel and confusing situations with complicated problems where simple intuitive rules can help people to move forward. Luecke (2007) framed intuition as a "smell test" of the fact-based analysis. When the two approaches are in disagreement over a specific topic, then the decision should be delayed and further information sought until the two sides are in agreement.

\section{Empirical Studies of Intuition and Decision Making}

The number of empirical studies are few, in fact: "Field research [on intuition] in applied management settings is quite sparse” (Khatri \& $\mathrm{Ng}$, 2000, p. 59). Studying the role of intuition in strategic decision making Khatri \& Ng (2000) found that for intuition to be effective it requires years of experience in problem solving and that it is founded upon a solid and complete grasp of the details of the business. Also, they found that "the use of 'gut feeling' in strategic decision making in the computer industry was much greater than in 
banking and utilities” (ibid, p. 77). Agor (1986) showed how managers use intuition for strategic decisions, such as whether to invest capital in a project. Burke \& Miller (1999) found that intuition is based on experience, that it is used to fill in blanks when quantitative data is lacking in strategic business decisions, and that experienced people use their intuition more. Raidl \& Lubart (2000-2001) showed that intuition involves a process of linking disparate elements of information, and finally, Behling \& Eckel (1991) found that intuitive decision making produces choices more rapidly than its analytical counterpart. In a recent study Woiceshyn (2009) examined the how CEOs combine rational analysis and intuition. Her findings showed that the two approaches interact constantly in the information management process used by effective CEOs in decision making.

The value of intuitive holistic associations is praised by scholars focusing on the use of intuition by experts in specific domains. In a study of a group of technical experts, Hammond et al. (1997) found that intuitive reasoning is at least as good as rational analysis in the case of complex problem solving, when perceptual approaches to interpreting information is needed. Implicit learning or intuitive expertise is developed when people perform complex yet practical tasks. The expertise is developed subconsciously before the manager can consciously detect the behavioral patterns of information acquisition and use it in the corresponding task (Lewicki et al., 1992). According to Sparrow (2000) the managers who use intuition in practical tasks show higher levels of skilled performance.

Expertise based intuition has been praised by various researchers investigating specific groups of people such as chess players, firefighters, surgeons making critical decisions, and military personnel during combat (for an account of these studies see Kahneman \& Klein, 2009). Common in all this studies is the ability of the expert to make unconscious associations, which provide a holistic perspective. They highlight the importance of specific patterns of recognition by the intuitive person (Klein, 1998). The effectiveness of the use of intuition in relation to unstructured, or ethical problems in public schools has been underlined by Davis \& Davis (2003).

\section{A Baseline for Future Empirical Research on the Use of Intuition in Decision Making}

In some ways the different perspectives on and empirical studies of the use of intuition in decision making provide contradictory results of the use and effectiveness of intuition by managers. There are various definitions of intuition coming from different streams of research, and being based on different assumptions. We adopt Dane \& Pratt's definition of intuition being "a non-conscious process (2) involving holistic associations (3) that are 
produced rapidly, which (4) result in affectively charged judgments” (p. 36, 2007). Especially, they emphasize that "the holistic associative properties of intuition involve recognizing patterns or other linkages among disparate stimuli” (ibid, p. 39), and that experts have complex cognitive maps that trigger effective intuitive judgments. Furthermore, Dane \& Pratt (2007) suggest that there is ample space for intuition in decision making. For example, intuition is effective when it is used by domain experts in the area of their expertise or when it is used for unstructured problem solving where the manager's judgment is required. The Mann Gulch disaster (Weick, 1993) is a reference story in which acting on intuition resulted in the survival of some individuals and the death of the others. According to Miller \& Ireland (2005) because decision makers are unable to "sell" their intuition in an explicable way, commitment by others tends to be low and they do not follow.

\section{EMPIRICAL CONTEXT FOR PROJECT PRIORITIZATION}

Our empirical context is a Scandinavian financial institution. The organization has a strong tradition for the use of objective measures, such as cost-benefit analysis, as input to decision making in all aspects of its activities. The study was undertaken in the organization's IT unit, which is in charge of standardizing, automating processes and developing IT systems to enhance efficiency in the organization. The IT unit is headed by the chief information officer (CIO). It employs more than 800 people and is divided into seven development areas, each of which is headed by a development director. A development area is divided into departments (38 departments in total), each of which is headed by a development manager. In order to achieve its objectives, the IT unit collaborates closely with representatives of the business units of the organization, and the so-called business representatives are heavily involved in the project prioritization processes.

In the subsequent sub-sections we lay out the project prioritization process. First, we describe a typical prioritization meeting, and thereafter, we present the activities undertaken by decision-makers before prioritization meetings.

\section{A Project Prioritization Meeting}

A project prioritization meeting takes place in a Prioritization Group (PG), which governs the activities in a specific section of the IT unit. In a project prioritization meeting it decides on the list of projects to be undertaken by that section in the year to come. The participants in the meeting are the members of the PG, which are a development manager (serving as its secretary), the development directors of the departments that are governed by the specific PG, 
and the development directors of other interrelated areas. Additionally, business representatives, sponsoring the proposed projects, IT people specialized in the respective domains, the $\mathrm{CIO}$, and the $\mathrm{COO}$ (Chief Operation Officer) participate in the meeting. Typically 8 to 13 people participate in a project prioritization meeting.

The PG secretary is responsible for managing its prioritization process in the PG. The PG meets four times per year, i.e., quarterly. In the Q3 meeting, the PG secretary hands out a preliminary list with projects for the next year to the members of the PG. Finally, in the Q4 meeting the PG meets in order to decide on the list of IT projects that will receive funding in the coming year. In the Q1 and Q2 meetings, the PGs follow up on the running projects.

Before a prioritization meeting, the PG secretary prepares a slide presentation, which includes the agenda as well as a preliminary prioritization list. All projects are presented in a spreadsheet (see Figure 1), which includes standard information for each project such as net present value, cost estimates, full time employees (FTE), benefits, time schedule, subdeliveries, and releases.

\section{FIGURE 1}

Prioritized List of IT Projects in a Spreadsheet as Presented in Meetings

\begin{tabular}{|c|c|c|c|c|c|c|c|c|c|}
\hline Development Plan 2011 & & $\begin{array}{l}\text { Expected } \\
\text { size (FTE) }\end{array}$ & Cost 2011 & Cost total & $\begin{array}{c}\text { Benefit } \\
2011-2015\end{array}$ & Benefit/Cost & G-ITC & Project & Strategic \\
\hline Project / Avtivity & Priority & Vgt.2011 & M DKK & MDKK & MDKK & Ratio & Focus Areas & Status & Direction \\
\hline Projecta & 1 & 7 & 6,3 & 6,3 & 4,8 & 0,8 & 2 & Active & Run the business \\
\hline Project b & 2 & 5 & 7,4 & 9,4 & 10,2 & 1,1 & 2 & Active & Improve the business \\
\hline Project $x$ & 3 & 11 & 15,6 & 15,6 & 54,9 & 3,5 & 2 & Active & Costreduction \\
\hline Projecty & 4 & 9 & 10,4 & 10,4 & 4,3 & 0,4 & 3 & Planned & Process Efficiency \\
\hline Project z & 5 & 2 & 3,6 & 4,5 & 13 & 2,9 & 3 & Planned & Customer Experience \\
\hline Projectk & 6 & 5 & 4,5 & 8,3 & 0 & 0,0 & 3 & Planned & Compliance \\
\hline Project c & 7 & 8 & 8,5 & 8,5 & 33 & 3,9 & 7 & Planned & Cost reduction \\
\hline Project d & 8 & 7 & 9,5 & 9,5 & 22 & 2,3 & 3 & Planned & Process Efficiency \\
\hline Sum & & 54 & 65,8 & 72,5 & 142,2 & 14,9 & & & \\
\hline
\end{tabular}

The list is altered during the meeting, as decisions about the ranking of the projects are made. A core criterion used in the pre-prioritization of projects is the cost-benefit ratio calculated for each project. Other criteria used are the fit with organizational strategic focus areas or the strategic directions of the sponsoring business department. The presentation by the development manager includes; a) the ongoing projects, b) the compliance projects undertaken in order to ensure fulfillment of current legal requirements, and c) new business projects. For new business projects, the cost-benefit ratio serves as the starting point of the discussion, while project specific arguments follow.

The list of proposed new business projects includes more projects than a PG can accommodate within its budget, and thus, a PG's resources are allocated to the new business 
projects with the highest priority. Ongoing and compliance projects are considered mandatory for the organization, and thus, in prioritization meetings discussions focus on the new business projects, and existing projects that require additional resources.

For the new business projects the sponsor of the project idea presents the facts of the proposal and is challenged by other members to explain the business rational behind the project, e.g., cost savings compared to other project proposals in the list. The sponsor responds by putting forward arguments in order to explain the rationale behind the project. The challenging and argument development continue until the participants in the meeting agree about the priority of the project.

\section{Activities before the Project Prioritization Meetings}

Before the prioritization meetings the organization prepares proposals for new business projects to go into the prioritization process. Typically, the preparation of a project proposal includes three sets of activities:

a) Generation of New Project Ideas. The process of suggesting and developing project ideas typically begins at a lower level in the organization (bottom-up). Some project ideas are initiated in the business units and others are initiated in the IT organization, and subsequently they evolve in debates between development managers, business representatives, IT project managers and IT developers. When an idea begins to mature, an IT project manager, a business developer, or a business representative, is assigned to develop a memo for a potential project. Memos are one to two pages long. A typical memo includes a description of the problem or opportunity that the new project addresses, a rough cost and benefit estimate for the project, or a qualitative description of the expected benefits, and finally, a preliminary technological solution and a potential time schedule for the project. The amount and the quality of the information in the memo vary from memo to memo depending on the maturity of the idea.

b) Consultation About and Review of New Projects. In the process of developing the memo into a full project proposal, a development manager takes over responsibility for the process. They ask their groups to produce more detailed cost estimates for each new project, and they make contact with IT developers and IT project managers, in order to investigate the technical feasibility of the project idea: "We call the ones that we really know can make it and ask them if I need a product in a week can you do it or not and then there it doesn't work to go into the 
real prioritization part because then I will never get something, I will not get it in 100 years." (Interview with Senior Business Representative 2, May 2010, page 15) When a preliminary full project proposal is available it might go through an internal review process by a business analyst from the IT unit. This quality check may lead to revisions of the project proposal. Once the review is conducted, the development manager brings the project proposal to the chairman of the PG, who is the CIO, the COO or a business representative. Also, at this point the development manager begins to look for sponsors in his or her network, in order to secure the inclusion of the project proposal in the prioritization list. "If you have some [projects] that you think are absolutely important then you try and get some friends to back you up in the PG, I think that's a fairly natural process.” (Interview with Senior Business Representative 3, June 2010, page 19)

c) Informal Discussions of Project Proposals. Once the cost estimates have been provided for the project proposals and the development manager together with the business representatives in the PG have created an opinion about them, then they meet informally and discuss the project proposals. In these bilateral meeting they discuss the projects and express their beliefs about them, and their importance and priorities. Also, they exchange information about the resources that are available to the PG in the coming year, since they put a limit to the number of new projects the PG can initiate. "Many of the things are already cleared before we come to the meetings in order to find out how many resources do we actually have for new development parts” (Interview with Senior Business Director, May 2010, page 4). When it comes to the project choice per se a senior business representative reported: “... at the end of the day [we] look at [the projects] and say what is my feeling ... about this ... project" (Interview with Senior Business Representative 1, May 2010, page 11).

Based on these informal meetings the secretaries of the PGs compose preliminary project lists, which they bring to and present at the PG meetings. Also, before a PG meeting the PG secretary typically communicates with the development directors, in order to briefly discuss the agenda, as well as potential issues that might emerge during the meeting. Finally, before the prioritization meeting, the chairman of the PG investigates the opinions of the different stakeholders (e.g., Financial Director, COO, and business representatives from different units), in order to be better prepared for the PG meeting. 


\section{RESEARCH METHOD}

An in-depth case study was conducted in order to explore the IT project prioritization process and how decision making is practiced in this context. Such a case study is particularly appropriate for exploratory research where a thorough understanding of a phenomenon in its context is preferred (Benbasat et al., 1987; Yin, 2003).

\section{Data Collection}

The empirical data was collected over a period of approximately eight months, focusing on project prioritization for 2011 in two PGs. In order to understand such a process in a complex organization, the researcher must be familiar with the context in which it takes place. Hence, the collection of empirical data had the dual purpose of establishing this familiarity with the organizational context, and of documenting the project prioritization process itself. To that end several data collection techniques were applied; real-time observations, recording of meetings, semi-structured interviews, and collection of written documents produced by the organization.

Real-time observations took place in two subunits of the IT unit where a researcher observed managers in their natural setting. The observations primarily served to establish an understanding of the activities of the two subunits and the context in which the project prioritization takes place. Field notes kept during the observations also served as background information for the interviews and the meetings.

The richest sources of empirical data about the prioritization process are eight recorded meetings, which were transcribed ad verbatim (approximately 170 pages), and 43 semistructured interviews with the managers (see Appendix A for information about the distribution of the interviewees in the organization), which were also transcribed ad verbatim (approximately 730 pages). As we studied a largely unexplored phenomenon, the study design was not strictly defined in advance. Instead, it followed an evolutionary, iterative approach where the activities of data collection supported each other throughout the process. For example, the meeting observations were used as input to the follow-up interviews that were conducted in a later stage.

Initially we conducted semi-structured interviews (from April to June 2010) with employees at different levels and from different units in the organization, who participate in PG meetings. The interviews provided personal views of the prioritization process, its context and the history of the process. From these interviews two main stakeholders in the process were identified. First, the IT unit, which owns the project prioritization process and executes the prioritized projects. Nineteen interviews were performed with employees from the IT unit at 
different levels of seniority. Second, in the business units, eleven representatives at different organizational levels were interviewed. All interviews were semi-structured, and open-ended questions were asked about the prioritization process. Each interview lasted on average 50 minutes.

Second, we observed meetings (from June to October 2010) where the participants prioritized the projects. We followed two subunits of the IT unit and participated in the prioritization meetings of the PGs they are involved in. From these meetings we collected documents such as meeting minutes, presentations given at the meetings and any other material that was distributed to the participants before the meeting.

As a follow-up on the recordings of the meetings we conducted thirteen semi-structured interviews with participants in the meetings (from October 2010 to April 2011) and reviewed additional background material. The additional background material included documents, such as power point presentations, meeting minutes, forms, spreadsheets, reports, organizational charts and memos (See figure 2 for a timeline for the data collection process). A documentation study was applied in order to gain insights into the organization's prioritization process and to triangulate the data sources with the interviews and the meeting observations (Lee, 1999).

\section{FIGURE 2}

\section{Data Collection Timeline}

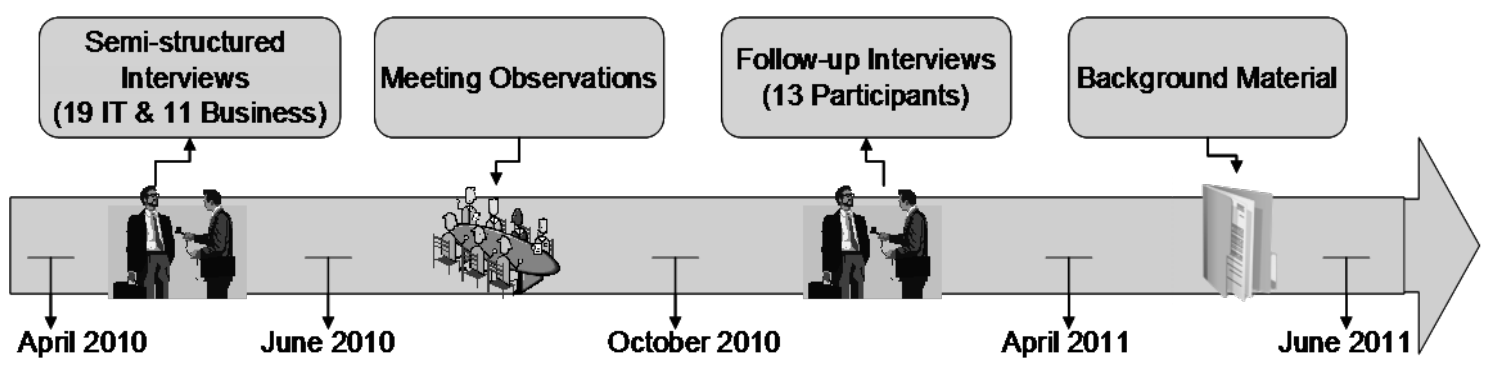

\section{Data Analysis}

For the purpose of; a) getting a detailed overview of the empirical setting, and b) identifying indicators of the how the prioritization processes unfolds, we carefully read all of the transcripts of the interviews and the meetings, as well as the background material and field notes. In order to investigate our research questions, we employed constant comparative techniques (Strauss, \& Corbin, 2008; Suddaby, 2006) where we analyzed the data in a systematic and iterative manner. 
During this process we adopted an "insider-outsider” interpretive approach (Bartunek et al., 1996; Gioia et al., 2010) where initially one researcher established the "insider" perspective of how IT project prioritization is practiced in the organization. Once the "insider" understanding was formed, the other researchers engaged on a more abstract theoretical level, the so-called "outsider" point of view where they created a link between the two perspectives (Corley, \& Gioia, 2004). In other words, we merged the “insider” understanding of practice with the "outsider" understanding of the existing literature.

The author conducting the entire fieldwork developed an "insider" view of the process, whereas the other authors looked at the data after they were collected. Having an "outsider" perspective on the phenomenon of interest and the research site, they provided new ways of theorizing and identified patterns in the data, which were subsequently discussed with the author holding the 'insider' perspective. This analytical approach was fruitful as the author holding the 'insider' perspective could draw on her rich understanding of the data during the discussions of the identified patterns by agreeing or disagreeing with the other authors, and thus, link the "insider" view with existing literature. Hence, the analysis evolved into an iterative process where data was compared with emerging themes in a cyclical process inspired by Miles \& Huberman (1994). As a first step in the data analysis we developed an overview of the project prioritization process. This overview facilitated our understanding of the prioritization process. In the next step, we read all documents and meeting transcripts to identify components of raw data across the different sources. We especially searched for passages, which captured ideas and themes such as 'cost', 'benefits', 'intangible benefits', 'gut feeling', ‘judgment', 'linking of disparate elements', 'holistic associations', 'experience’ and 'prioritization criteria'. We organized these first-order codes into tables that supported a single theme across the various data sources inspired by the in-vivo coding technique (Strauss, \& Corbin, 2008). In the next step, we developed the second-order themes by focusing on how decision makers introduced intuitive judgments in the prioritization process, and how intuitive and analytical arguments interacted. Once we sorted the raw data, we further analyzed the data in an attempt to identify higher-order themes by looking for patterns and overlap among second-order categories, the so-called axial coding technique (Strauss \& Corbin, 2008). This analysis was conducted in several iterations until the authors agreed to the final themes and no further overlaps occurred between the themes. In the final step, through an iterative analysis "associative inclusion of non-measurable properties of project", “joint promotion of intuitive judgment”, “reframing of project facts” and "activation of 
experience-based domain knowledge" emerged as observable phenomena in the data (Eisenhardt, 1989).

\section{ANALYSIS OF INTUITION IN PROJECT PRIORITIZATION}

We analyze the use of intuition in project prioritization processes, in four instances where the participants in PG meetings argue about the prioritization of specific project proposals. As stated previously, we investigate how decision makers apply intuition during these meetings. We also present the different forms of expressing intuition during these meetings, and later we look at under what circumstances the different uses of intuition become decisive in project prioritization. Please note that names of the firm and the individuals portrayed in the analysis have been changed in order to preserve their anonymity.

\section{Prioritization of a Project with a Weak Business Case}

The first instance is from a PG meeting, which lasted one hour and forty minutes. The meeting had ten participants, four business representatives (three business directors and a business analyst) and six IT representatives (the CIO, the COO, three development directors and the PG secretary). The list up for prioritization included 16 projects, of which five were discussed during the meeting.

\section{Actions}

a) The PG secretary presents the new business project A. Compared to other projects, project A's cost-benefit ratio is moderate. Yet, he asks the participants to remember that the idea qualification, which was provided to all the members before the meeting described the project as driven by strategic reasons and not by its cost-benefit ratio.

b) The COO asks if the project impedes the implementation of other projects with more attractive business cases.

\section{Interpretations}

When presenting the new project the PG secretary seeks to influence the participants to associate the project with its strategic importance when judging the project proposal.

The COO attempts to challenge the association suggested by the PG secretary by referring to opportunity cost. 
c) The PG secretary agrees that the cost -benefit for project $\mathrm{A}$ is not "phenomenal", but explains the project will not delay other projects in the pipeline. He explains that the project represents an important investment, because in the future the organization has to change all the old systems, and this project is a first step in this change process.

d) The PG secretary explains that they took into account the benefits from customer experience (soft facts), and placed these in a column next to the financial measures. In the prioritization table the benefit is derived from the sum of both.

e) A senior business representative enters the discussion stating: "this is not necessarily in my perspective the best business case I have ever seen. I would have liked to use more effort in project B in order to complete all the deliverables, which are delayed...”

f) The PG secretary responds with two arguments. First, the size of the ongoing project mentioned by the senior business representative is too big, and thus, the available resources are not sufficient. Second, the available human resources do not hold the competences needed in the ongoing project, and thus, they cannot be transferred from the proposed to the ongoing project.

g) The senior business representative understands the arguments, however he states that his preferences are different: "seeing it from a business perspective and also from the perspective of having the right system in the future, I really think that it [Project B] has priority for me”.
The PG secretary addresses the opportunity cost argument, and applies his domain knowledge to associate the new project with the future needs of the organization.

Contrary to the normal procedure, the PG secretary added soft facts in the cost benefit analysis, in order to inflate the importance of the quantitative measures.

Based on his personal judgment the senior business representative challenges the decision to prioritize the new project, and proposes to allocate the resources to an ongoing project.

The PG secretary uses his domain knowledge to counter argue the senior business representative's suggestion to shift resources in the ongoing project.

The senior business representative associates the business perspective with future needs for IT expresses why he prefers the ongoing project. 
h) A development director, who seems convinced by the doubts of the senior business representative, steps in and informs the PG secretary that: "it just might be, in general terms, that there might be a conflict with other similar projects, and therefore, we might consider to postpone it, because if we have other good new projects that can consume the resources, then it might be a trade off."

i) The PG secretary reacts immediately by summarizing all the reasons that he has stated previously "I really don't follow you, because it actually fits well at the moment and it suits the competences we have at the moment ... seen from a customer perspective”. Despite the weak business case, the arguments put forward by the PG secretary convince the participants in the meeting to keep the project in the list.
The development director applies his detailed domain knowledge when judging the concerns to express the senior business representative, and introduces an alternative.

The PG secretary quickly links dispersed elements, such as customer perspective and resources, and put forward his judgment; that it makes sense to prioritize and keep the project in the list.

In this instance the participants in the meeting challenged the prioritization of a new project with a weak business case, which is build on a combination of estimated tangible and intangible benefits. Mainly, the debate unfolded between two participants in the meeting, the PG secretary and a senior business representative, who debated alternative uses of the organization's resources. The PG secretary continuously linked disparate elements in an associative way, in order to make a case for the prioritization of the project, and against the use of resources in an alternative project. In contrast, the senior business representative applied his experience to argue against the proposed project because of the weak business case and for the alternative use of resources in the other project he supported. In this case two meeting participants with opposing views applied intuitive thinking, but the PG secretary who actively associated the disparate elements, which other participants also considered came out stronger than the senior business representative who put forward judgments based on his own experiences.

\section{Prioritization of a Project with Small Benefits}

The second instance is from a PG meeting that lasted two hours. The meeting had eleven participants, five senior business representatives, and six IT representatives (the CIO, three development directors, a development manager, and the PG secretary). Fourteen projects were presented in a prioritized list and five of these were discussed in the meeting. 


\section{Actions}

a) After the PG secretary's presentation of the list of projects, an IT-manager comments on a project's benefits calculations: "[for project $Y$ ] the benefits are very small compared to other [projects] we start and I was thinking ... is it the right thing to start a project with such a rather poor benefit case rather than putting all the resources on where we really can see that we can get the benefit right away."

b) The PG secretary emphasizes other intangible criteria which he perceives as important: "we think that is an okay business case here and we would like to challenge ourselves in the terms of customer experience, we think that we need to take that into account that's as good as other kinds of benefits and we actually quantified some of the benefits seen from a customer point of view and we really think that these also are valid as arguments for the project, but this is as I just said the first part of it, of a longer strategy that would actually have substantial benefits, it's more like how do we want to manage in terms of our projects that we would like to size it up. So it's connected very much to the next project that we would like to start up and it will be a better benefit case for the coming projects.”

c) In an attempt to show that other participants share his idea, the PG secretary asks another participant for his comments: "John you have [something to say]?” John: "I must say that the number of project steps that we aim at is large, so it's a very complex area and you can try to solve it all in one project it will probably never end. So I have to say that although it seems as the benefit is small this is putting out of foundation for future work."

\section{Interpretations}

The IT manager intuitively challenges the expected low benefits and considers the opportunity cost in relation to other projects having immediate benefits.

The PG secretary reacts by emphasizing the intangible benefits of the proposed project. He links otherwise disparate considerations about the project's potential benefits in an associative manner, in order to support the project, and he suggests that future projects will benefit from the proposed project. Thereby, he puts forward a holistic perspective on the project.

The PG secretary gets support from a meeting participant with domain knowledge, who takes on a holistic perspective when judging the complexity of the problem to be addressed by the proposed project and its importance to future projects. 
d) The CIO enters the debate, stating: "Maybe, maybe the right thing would be to show the benefit of the first step, but also perhaps indicate the full potential,...because the full potential is much bigger ... I think when we see the full [potential] ... I have a feeling that it's right, but then you have to have the picture."
The CIO enters the discussion and intuitively he, based on affectively charged judgment [I have a feeling], suggests alternative calculations and presentations of the benefits in order to demonstrate the full potential of the pro-posed project.

e) A senior business representative also comments on the benefits: "I think that it could be nice to, be sure when we have specially our presentation for the [group committee] that we will be able, in one slide to show them the road map on where to go with this and where on the benefits and this because it is a little tricky to come up and say well we have this project taking here and we don't get anything out of it."

f) The participants decide to keep the project but change the presentation of the proposed project's benefits to reflect its benefits for future projects.
The senior business representative supports alternative presentations of projects, as he intuitively [it could be nice] experience they will help to clarify the project's benefit to the organization.

The meeting participants decide to keep the proposed project, but to ask for a revised presentation of its benefits, which can support their intuitive understanding of it.

In this instance the quantitative measures of the proposed project's benefits, included in the presentation, could not justify the prioritization of the project, which the meeting participants strongly wanted. For the purpose of justifying their prioritization of the project to the rest of the organization they introduced a holistic approach, which allowed them to link the various positive elements of the project into a convincing case. Thus, the participants in the meeting asked for a revised presentation, including alternative calculations that altogether could capture their intuitive judgments of the project. 


\section{Prioritization as Project Swapping}

This third instance took place in the same meeting as the second instance, above.

\section{Actions}

a) A development director suggests the replacement of a priorityzed project with a non-prioritized project, as he anticipates it will be more costly to undertake the non-prioritized project later, due to a future lack of competent resources in the organization. Both projects are directly related to the development director's responsibilities and the change in priorities only holds consequences for his part of the organization. "I think if we should [do project z], it's now. I just think we should do it now because it's the best for the group and the customers to do that in this window of opportunity”

b) The CIO and another development director asks for more information on why this is a window of opportunity.

c) The first development director argues that the future business case will be very different from the current one because many employees holding the domain knowledge needed to carry out this project are approaching the retirement age, and thus, in the future the organization is likely not to possess the competences needed to undertake the project. A situation, which he expects will have adverse implications for the business case.

d) The CIO prompts the participants in the meeting about an alternative solution to the problem anticipated by the development director.

\section{Interpretations}

The development director applies his domain knowledge to suggest swapping of two projects in the list, as he believes it is the right time to do the non-prioritized project.

Two colleagues of the development director attempts to test the intuitive judgment expressed by the development director.

Combining several pieces of disparate information, the development director intuitively believes that the costs of the non-prioritized project will increase in the future.

The CIO challenges the belief of the development director by investigating whether alternative solutions exist. 
e) The development manager steps in by emphasizing that no matter which solution is chosen the project will cost more, unless it is done at this point in time, and that the customer experience would deteriorate because of the existence of two different systems.

f) A third development director summarizes the first development director's suggestion "if I understand you correctly you want to swap item 10 with item 19. From the gross numbers involved in either of the case it appears that the number of projects you would be able to handle, it's a little bit more on safe ground”, He points out that the non-prioritized project requires less human resources than the other project, which is preferable since the resources for the area has been stretched to the limits. However, he also draws attention to the increased uncertainty and the higher risks for the suggested project compared to less uncertainty and risks of the other project.

g) The participants in the meeting consider the increased risks but decide to swap the projects and prioritize the project as suggested by the development director.
The development manager supports the proposed project swapping, by making a holistic association between costs and customer experience.

Based on his judgment of the capacity, in terms of available resources, to undertake the project, a third colleague supports the proposed swapping of projects in the list, while highlighting the risks involved.

The participants in the meeting are convinced and swap the projects.

In this instance the development director drew on his domain knowledge and intuitive belief about future project costs and he proposed a re-prioritization of two projects. He articulated his concern about whether the organization could complete the non-prioritized project in the future without additional high costs, if the project swapping was not decided. After a speedy consideration of alternative solutions, two other participants in the meeting supported the proposal put forward by the development director. Especially, they supported his intuitive judgment, in an attempt to avoid imposing the cost of uncertainty he anticipated.

\section{Prioritization of an Urgent Project}

The fourth instance is from a meeting which lasted one hour. The meeting had nine participants, of which six were IT representatives (three development directors, the CIO, a development coordinator, and the PG secretary) and three business representatives (a business director and two product managers). The list presented by the development manager included eight projects. Here the instance is selected to show a case where a new project outside the 
proposed list is sent by a business representative at the last minute (one day before the meeting).

\section{Actions}

a) The PG secretary presents a new project, which was distributed to the participants by a business representative, one day before the prioritization meeting. The PG secretary provides the historical background of previous related decisions and concludes by saying "I would like to draw your attention to two things; The main thing here is that the benefit that we have seen is solely from hitching opportunities. The product characteristics are that this is full grown home loan product that has all the features that should be there, is not a tactical solution.” The PG secretary challenges the benefit of the project in relation to other projects. While he recognizes that the quality of the product will be high, he doubts the benefits that can be de-rived from the project since they are based on exploiting a temporary opportunity.

b) A senior business representative emphasizes that the project has been discussed several times in the PG, but in the past it has always been postponed. Also, while he recognizes that the costbenefit ratio is not good, then he argues that the project is critical for a specific market since all the competitors already offer it. "All the rest of the competitors in the market compare themselves against this product, which mean that if you look up in the papers just once you will actually see that what they compare in the market will be this [specific] product and we are the only company that are not able to show this".

\section{Interpretations}

The proposed project is introduced as a hitching opportunity, and as a comprehensive solution. Yet, the development manager intuitively doubts about the expected benefits of the project.

The senior business representative, who proposed the project, acknowledges its weak business ca-se, but taking on a holistic perspective he assesses that it is of high importance for the competitiveness of the organization. 
c) The PG secretary presents all the alternatives to the proposed project and the consequences of each alternative if included in the current plan. The first alternative is to develop the product for the old platform (new platform is being developed). The consequence of this alternative is the delay of other projects in the list and a product delivery in 6 months. The second alternative is to incorporate the product as a change request to the new plat-form under development. The consequence of this alternative is a delay in the completion of the new platform, higher risks, as well as a delay of another project in the list, and a product deli-very in 7 months. The third solution is to swap the proposed project with another project in the list. This means that the project will be delivered in 9 months. Each alternative is discussed, but information is missing so the discussion gets nowhere.

d) While presenting the alternative, the PG secretary argues that the proposed project should not be included in the list. Especially, he argues that even if it could be included in the list with no consequences for other projects, then alternative projects with better prospects has already been proposed.

e) The senior business representative responds: "I agree that we could find products in the world that it would make better sense to make than this one, I think that the biggest benefits of this is the [specific] market and that it can bring us back into the competition".

f) Several participants in the meeting ask about other alternatives or ways of changing current alternatives, in order to avoid negative consequences (e.g., delays). A lot of “what if” questions are asked, but no concrete answers materialize.
The introduction of a set of alternatives to the proposed project introduces new uncertainties, and makes it difficult for the participants in the meeting to assess the appropriateness of the various alternatives.

The PG secretary challenges the expected benefits of the proposed project, by underlining the opportunity costs.

The senior business representative applies his experience and domain knowledge when arguing that the project will enable the organization to compete in the specific market.

The participants in the meeting reflect on the alternatives, but their experience and knowledge about the domain is not sufficient to form the basis for intuitive judgments, and thus, make up for the lack of concrete information. 
g) The participants in the meeting agree that they lack information to make a decision, and thus, they decide to initiate further inquiries about the project and ask for development of business cases for the alternatives. The senior business representative and the development manager agree to develop the business cases and to submit it to the PG when it is ready.
The project prioritization is postponed until the business case and additional information about the alternative are available.

In this instance the intuitive judgment of the senior business representative who introduced the urgent project could not make up for the doubts raised by the PG secretary about its expected benefits. The PG secretary introduced alternatives and discussed their consequences with the other participants in the meeting. This raised additional questions and underlined the lack of information of the participants about the new project, which in turn resulted in a postponement of the decision. The positive judgments made by the senior business representative, based on his experience, did not influence the managers in the final decision.

\section{DISCUSSION OF FINDINGS}

In this study we investigated how decision-makers use intuition in decision-making and below we discuss four techniques that decision makers apply when they attempt to make space for intuition during project prioritization meetings. Our findings build on and advance the research by Dane \& Pratt (2007), as it shows how intuition is used in an organization that prescribes structure and specific criteria for project prioritization, for example in the form of quantitative measures of costs and benefits. More precisely, we observed how decision makers use intuition during group decision making, where established technologies of rationality (March 2006), such as cost-benefit analysis, are widely used.

\section{Making Space for Intuition in the Project Prioritization}

In large and complex organizations intuition is seldom canonized as a legitimate basis for decision making. Instead, decision makers are expected to use tools developed to support analytical decision making. However, in the present study we found that decision makers apply specific techniques, which enable them to make space for the use of intuition in decision-making processes.

In an attempt to structure the IT project prioritization process, the organization prescribes the use of cost-benefit analysis as a central selection mechanism in project prioritization, and it supports this mechanism with state-of-the-art technologies, which enable collection and 
analysis of quantifiable data about costs and benefits for potential IT projects. However, by nature the projects also involve intangible benefits as well as unforeseen contingencies and uncertainties, which influence the realized costs and benefits. Thus, in order to address the loosely structured problem of project prioritization, decision makers apply different forms of judgment and they often take on a holistic perspective when assessing a project proposal. In total, we identified four techniques through which decision-makers create space for intuition in IT project prioritization.

Associative inclusion of non-measurable properties of projects. One technique for making space for intuition can be observed when a project has intangible benefits, which a decision maker assesses as crucial for capturing its importance to the organization. In such a situation the decision maker intuitively judges the magnitude of the intangible benefits and their expected impact on the organization. This judgment is based on the decision maker's experience and domain knowledge. Decision makers include the intangible benefits when arguing about the prioritization of a project without being able to explicitly describe how these benefits will be achieved. For example, in the first instance the PG secretary argues for inclusion of the project based on its intangible benefits, in the form of its strategic importance, which he perceives as very important to capture the impact of the project. Furthermore, he associates the project with systems to be developed in the future by presenting it as the first step in a change process.

Joint promotion of intuitive judgment. Another way of making space for the use of intuition during group decisions is joint promotion of intuitive judgments by more decision makers. This makes the intuitive judgment more acceptable, or legitimate. The decision maker who introduces an intuitive judgment in the discussion asks for the opinion or support of another decision-maker, which indicates trust in the promoter of an intuitive judgment, and reduces the concerns in the rest of the group about the validity of the judgment. For example, in the second instance, the PG secretary actively asks for the opinion of another senior (powerful) member who supports his judgment.

Reframing of project facts. When decision makers assess that the estimated measures are insufficient to make the desired prioritization of a proposed project appear convincing to the rest of the organization, alternative framing project facts, for example, the calculations, is employed. The reframing is performed in order to make the project facts look better, for example, by including additional projections of future benefits, and thereby, provide support and better justification for their intuitive positive judgment of the proposed project. Use of the reframing technique reflects that decision makers take on a holistic perspective when 
assessing the project in question, and they appear to be more prone to do so when they a priori have judged the project to be important. We observe framing tactics on the project facts in the second instance where one of the decision makers proposes to recalculate benefits in a different way in order to justify the inclusion of a project in the list with small quantifiable benefits.

Activation of experience-based domain knowledge. Decision makers employ their personal knowledge to judge the importance of a project if they want a different prioritization outcome than the one resulting from the cost-benefit analysis. In such situations they bring their own opinion, supported by their experience and expertise in the domain under consideration to directly argue against the outcome produced by data analysis and estimates. For example, in the third instance, a senior decision maker argues, based on his inside knowledge and experience from a specific domain, for the importance of a project, which he succeeds to bring higher into the prioritization list. Conversely, in the fourth instance a senior business representative wishes to include a new project based on his judgment of the market readiness and the competitive position of the organization in this setting, but fails to convince the other decision makers. The main difference between the two debates is the use of associations which appeal to the intuition of the other decision makers. In the third instance associations about future cost increases, if the project was not chosen at this point of time, are used, whereas in the fourth instance the senior business representative fails to associate his insights with already presented elements in the prioritization process to which the decision makers can associate to.

\section{Contribution and Implications}

Our findings contribute to the scholarly literature on intuition in decision making. Responding to Dane \& Pratt's (2007) call for more empirical studies of the relationship between intuition and decision making, we investigated how decision makers apply intuition in decision making. More precisely, we investigated the role of intuition for group decision making, in the form of IT project prioritization. Our analysis showed that decision makers do indeed use intuition when prioritizing projects. By identifying four techniques used for making space for intuition in decision making, we contribute to a more complete picture of the role of decision making, especially, how intuition supplements the decision-making input produced with the use of rational analysis. Our findings also confirm the proposition that decision makers use intuition when facing loosely structured problems (Dane \& Pratt, 2007). In particular, we have shown, how intuition, often in the form of a holistic associative 
process, enables decision makers to integrate disparate elements of an ill-defined problem into a coherent perception of what counts as appropriate solutions to the problem.

\section{CONCLUSION}

Our study contributes to the debate over the role of intuition in organizational decision making. We investigated how managers use intuition in IT project prioritization decisions. The findings highlight the central role of intuition when decision makers are faced with loosely structured problems. We identified four techniques; associative inclusion of nonmeasurable properties of projects, joint promotion of intuitive judgment, reframing of project facts, and activation of experience-based domain knowledge, used for making space for intuition in decision making,

Our findings should be interpreted with caution since they are based in a single longitudinal case study, which even if it allowed for an in-depth investigation of the processes, cannot be claimed to produce generalizable the results. Therefore, further research should be conducted in different contexts, e.g. sectors, organization types, and cultures, in order to investigate the generalizability of the four techniques applied by decision-makers to create space for intuition in decision processes.

\section{REFERENCES}

Agor, W. A. 1986. The logic of intuition: How top executives make important decisions. Organizational Dynamics, 14(3): 5-18.

Albin, P. S., \& Foley D. K. 1998. Barriers and bounds to rationality: Essays on economic complexity and dynamics in interactive systems. Princeton. NJ: Princeton University Press.

Ballantine, J., Galliers, R. D., \& Stray, S. J. 1999. Information systems technology evaluation practices: Evidence from UK organizations. In S Lester (Ed.), Beyond the IT productivity paradox: 123-150. Chichester: Wiley.

Bartunek, J. M., Foster-Fishman, P., \& Keys, C. 1996. Using collaborative advocacy to foster intergroup collaboration - a joint insider/outsider investigation. Human Relations, 49(6): 701-732.

Bazerman, M. H., \& Moore D. A. 2008. Judgment in managerial decision making. Wiley.

Behling, O., \& Eckel., N. L. 1991. Making sense out of intuition. Academy of Management Executive, 5(1): 46-54.

Benbasat, I., Goldstein, D.K., \& Mead, M. 1987. The case research strategy in studies of information systems. MIS Quarterly, 11(3): 369-386.

Betsch, T. 2008. The nature of intuition and its neglect in research on judgment and decision making. In H. Plessner, C. Betsch \& $\mathrm{T}$. Betsch (Eds.), Intuition in judgment and decision making: 3-22. Mahwah: Lawrence Erlbaum Associates.

Bonabeau, E. 2003. Don’t trust your gut. Harvard Business Review, 81(5):116-123. 
Brynjolfsson, E., Hitt, L. M.; \& Kim, H. H. 2011. Strength in numbers: How does datadriven decision making affect firm performance? Available at SSRN: http://ssrn.com/abstract=1819486.

Burke, L. A., \& Miller, M. K. 1999. Taking the mystery out of intuitive decision making. Academy of Management Executive, 13(4): 91-99.

Corley, K. G., \& Gioia, D. A. 2004. Identity ambiguity and change in the wake of a corporate spin-off. Administrative Science Quarterly, 49(2): 173-208.

Crandall, B., Klein, G., \& Hoffman, R. R. 2006. Working minds: A practitioner's guide to cognitive task analysis. Cambridge, MA: MIT Press.

Dane, E., \& Pratt, M. G. 2007. Exploring intuition and its role in managerial decision making. Academy of Management Review, 32(1): 33-54.

Davenport, T. H. 2010. Bi and organizational decisions. International Journal of Business Intelligence Research, 1(1): 1-12.

Davis, S. H., \& Davis, P. B. 2003. The intuitive dimensions of administrative decision making. Maryland: Scarecrow Press.

Eisenhardt, K. M., 1989. Building theory from case study research. Academy of Management Review, 14(4): 532-550.

Gigerenzer, G. 2007. Gut feelings: Short cuts to better decision making. London: Penguin.

Gigerenzer, G., Todd, P. M., \& the ABC Research Group 1999. Simple heuristics that make us smart. Oxford: Oxford University Press.

Gilovich, T., Griffin, D., \& Kahneman, D. 2002. Heuristics and biases: The psychology of intuitive judgment. Cambridge: Cambridge University Press.

Gioia, D. A., Price, K. N., Hamilton, A. L., \& Thomas, J. B. 2010. Forging an identity: An insider-outsider study of processes involved in the formation or organizational identity. Administrative Science Quarterly, 55(1): 1-46.

Hammond, K. R., Hamm, R. M., Grassia, J., \& Pearson, T. 1987. Direct comparison of the efficacy of intuitive and analytical cognition in expert judgment. IEEE Transactions on Systems, Management and Cybernetics, 17(5): 753-770.

Hammond, K. R., Hamm, R. M., Grassia, J., \& Pearson, T. 1997. Direct comparison of the efficacy of intuitive and analytical cognition in expert judgment. In W. M. Goldstein \& R. M. Hogarth (Eds.), Research on judgment and decision making: currents, connections and controversies: 144-180. Cambridge: Cambridge University Press.

Hayashi, A. M. 2001. When to trust your gut. Harvard Business Review, 79(2): 59-65.

Hodgkinson, G.P., Sadler-Smith, E., Burke, L.A., Claxton, G. and Sparrow, P.R. 2009. Intuition in Organizations: Implications for Strategic Management. Long Range Planning, 42, 277-297.

Hodgkinson, G.P., Langan-Fox, J., Sadler-Smith, E., 2008. Intuition: A fundamental bridging construct in the behavioural sciences. British Journal of Psychology, 99, 1-27.

Hogarth, R. M. 2001. Educating intuition. Chicago, IL: University of Chicago Press

Kahneman, D. 2003. Maps of bounded rationality: Psychology for behavioral economics. American Economic Review, 93(5): 1449-1475.

Kahneman, D. 2011. Thinking, fast and slow. New York: Farrar, Straus, and Giroux.

Kahneman, D., \& Klein, G. 2009. Conditions for intuitive expertise: A failure to disagree. American Psychologist, 64(6): 515-526.

Khatri, N., \& Ng, H. A. 2000. The role of intuition in strategic decision making. Human Relations, 53(1): 57-86.

Klein, G. 1998. Sources of power: How people make decisions. Cambridge, MA: MIT Press.

Klein, G. A., Orasanu, J., Calderwood, R., \& Zsambok, C. E. 1993. Decision making in action: Models and methods. Norwood, NJ: Ablex. 
Lee, T. W. 1999. Using qualitative methods in organizational research. Thousand Oaks: Sage.

Lewicki, P., Hill, T., \& Czyzewska, M. 1992. Nonconscious acquisition of information. American Psychologist, 47(6): 796-801.

Luecke, R. 2007. When your gut speaks, should you listen? Harvard Business Publishing Newsletters, February: 1-2.

MacGregor, D., Lichtenstein, S., \& Slovic, P. 1988. Structuring knowledge retrieval: An analysis of decomposed quantitative judgments. Organizational Behavior and Human Decision Processes, 42(3): 303-323.

March, J. G. 1991. Exploration and exploitation in organizational learning. Organization Sceince, 2(1): 71-87.

March, J. G. 1994. A primer on decision making: How decisions happen. New York: The Free Press.

March, J. G. 2006. Rationality, foolishness and, adaptive intelligence. Strategic Management Journal, 27(3): 201-214.

Miles, M. B., \& Huberman, A. M. 1994. Qualitative data analysis. $2^{\text {nd }}$ edition. Thousand Oaks, CA: Sage.

Milkman, K. L., Chugh, D., \& Bazerman M. 2010. Intuition vs. deliberation: How decision making can be improved. Rotman Magazine, (4): 23-27.

Miller, C. C., \& Ireland, R. D. 2005. Intuition in strategic decision making: friend or foe in the fast-paced 21st century? Academy of Management Executive, 19(1): 19-30.

Mintzberg, H., \& Westley, F. 2001. Decision making: It's not what you think. Sloan Management Review, 42(3): 89-93.

Moore, D. A., \& Healy P. J. 2008. The trouble with overconfidence. Psychological Review, 15(2): 502-517.

Payne, J. W., Bettman, J. R, \& Johnson, E., J. 1993. The adaptive decision-maker. Cambridge: Cambridge University Press.

Pfeffer, J., \& Sutton, R. I. 2006. Hard facts, dangerous half-truths and total non-sense: profiting from evidence-based management. Boston, MA: Harvard Business School Publishing.

Prewitt, E. 1998. Fast-cycle decision making. Harvard Management Update, 3(8): 8-9.

Raidl, M. H., \& Lubart, T. I. 2000-2001. An empirical study of intuition and creativity. Imagination, Cognition and Personality, 20(3): 217-230.

Simon, H. A. 1955. A behavioral model of rational choice. The Quarterly Journal of Economics, 69(1): 99-118.

Simon, H. A. 1987. Making management decisions: The role of intuition and emotion. Academy of Management Executive, 1(1): 57-64.

Simon, H. A. 1992. What is an "explanation" of behavior? Psychological Science, 3(3): 150161.

Sparrow, P. 2000. Strategic management in a world turned upside down: The role of cognition, intuition and emotional intelligence. In P. C. Flood, T. Dromgoole, S. J. Carroll \& L. Gorman (Eds.), Managing strategy implementation: 15-30. Oxford: Blackwell Publishing.

Strauss, A., \& Corbin, J. 2008. Basics of qualitative research: Grounded theory procedures and techniques. $3^{\text {rd }}$ edition. Newbury Park, CA: Sage.

Suddaby, R. 2006. What grounded theory is not. Academy of Management Journal, 49(4): 633-642.

Tversky, A., \& Kahneman, D., 1974. Judgment under uncertainty: Heuristics and biases. Science, 185(4157): 1124-1131. 
Weick, K. E. 1993. The collapse of sensemaking in organizations: The Mann Gulch disaster. Administrative Science Quarterly, 38(4): 628-652.

Woiceshyn, J. 2009. Lessons from "Good Minds”: How CEOs Use Intuition, Analysis and Guiding Principles to Make Strategic Decisions. Long Range Planning, 42: 298-319.

Yin, R. K. 2003. Case study design: Design and methods. $4^{\text {th }}$ edition. Thousand Oaks, CA: Sage.

Appendix A: Information about Interviewees

\begin{tabular}{|c|c|c|}
\hline & IT unit & Business units \\
\hline $\begin{array}{l}\text { First round of } \\
\text { interviews }\end{array}$ & $\begin{array}{l}1 \text { Corporate level Officer } \\
7 \text { IT Development Directors } \\
3 \text { IT Development Managers } \\
5 \text { IT Analysts } \\
\text { 3 Portfolio Managers }\end{array}$ & $\begin{array}{l}3 \text { Senior Business Representatives } \\
7 \text { Junior Business Representatives } \\
1 \text { Business Analyst }\end{array}$ \\
\hline $\begin{array}{l}\text { Second round - follow } \\
\text { up interviews }\end{array}$ & $\begin{array}{l}2 \text { IT Development Directors } \\
2 \text { Portfolio Managers } \\
4 \text { IT Development Managers }\end{array}$ & $\begin{array}{l}2 \text { Corporate level Officers } \\
1 \text { Executive Member } \\
2 \text { Senior Business Representatives }\end{array}$ \\
\hline
\end{tabular}

